\title{
Solid waste management system: an impressive case study
}

\author{
V. Belgiorno \& D. Panza \\ SEED, Sanitary Environmental Engineering Division, \\ Department of Civil Engineering, University of Salerno, Italy
}

\begin{abstract}
The paper discusses the incomplete and debatable integrated municipal solid waste management (MSW) system adopted in Campania Region, Southern Italy, with regard to characterization and disposal of Refuse Derived Fuel (RDF) and Stabilized Organic Fraction (SOF). The integrated management system planned in Campania was characterized by a source-separated collection of $35 \%$ of the total MSW production and the treatment of the restwaste in MBT (Mechanical Biological Treatment) plants in order to obtain RDF, metals and SOF. Currently seven RDF/Biostabilization plants have been working, while the three expected thermal treatment plants are under construction yet. The MBT plants have the same productive cycle. Owing to scant source-separated collection as well as MBT plants inefficiency, RDF quality was inadequate, according to Italian regulation limits. Moreover, the produced RDF bales are stored in several regional sites: this temporary solution is very dangerous due to the risk of contamination and accidental burning. SOF is disposed of in worked-out quarries equipped like sanitary landfills, due to its poor quality.

Keywords: integrated municipal solid waste management system, refuse derived fuel, stabilized organic fraction.
\end{abstract}

\section{Introduction}

European and Italian regulations propose an integrated approach for waste management based on four hierarchical levels: (1) reduction of solid waste production, (2) recovery of material, (3) recovery of energy and (4) landfill disposal. Besides, the European Council Directive on the Landfill of Wastes $1999 / 31 /$ EC provides the reduction of landfilled biowaste to $35 \%$ of the amount produced in 1995 within 2016. 
As a result, Mechanical and Biological Treatments (MBTs) can be considered a necessary option in the waste to landfill path, in order to reduce organic fraction content and fermentability, strength of leachate, amount of biogas as well as settlement extent of waste (Panza et al. [1], Bone et al. [2], Bockreis et al. [3], Heiss-Ziegler and Fehrer [4]).

Moreover, MBT systems can promote the waste to energy path by means of Refuse Derived Fuel (RDF) production. Compared to untreated Municipal Solid Waste (MSW), RDF has a greater heating power value, a superior chemicalphysical homogeneity, a minor level of pollutant emissions and a minor air request during combustion (Belgiorno et al. [5]).

Particularly, MBT systems treat restwaste combining mechanical processes (shredding, sorting, fine/light/heavy fractions separation) with biological treatments. Two kinds of MBT systems can be identified: single-step or two-step model. In the first case, all the restwaste is biologically treated and the mechanical process is usually reduced to a mere crushing. In the second case, the biological treatment is carried out on the undersieve while the oversieve is directed to the energy recovery. Biostabilization and biodrying are two examples of MBT systems. Biostabilization or MBE (mechanical biological end composting) can be a single-step or two-step system while biodrying or MBS (mechanical biological and stabilate method) is mainly a single-step system (Panza et al. [1], Soyez and Plickert [6]).

In Italy, RDF from biodrying or two-step biostabilization can be burnt in specific thermal treatment plants or in co-combustion with other materials in thermoelectric power plants or in cement mill kilns, if it respects Italian regulation (Belgiorno et al. [5]).

Stabilized Organic Fraction (SOF) from two-step biostabilization can be used for environmental ends, such as establishment of wide green areas, reclamation of contaminated areas, layout of slopes and banks, restoration of worked-out quarries (Belgiorno et al. [7]). If it does not meet Italian regulation limits, it has to be landfilled as the final product of one-step biostabilization.

The paper discusses and investigates the integrated MSW management system in Campania Region, Southern Italy, as well as examines the quality and final destination of produced RDF and SOF.

\section{Materials and methods}

The integrated solid waste management system planned in Campania Region, Southern Italy, considered a separated collection of $35 \%$ of the total solid waste production, in order to promote composting and materials recycling and the treatment of the restwaste in MBT plants to obtain RDF, SOF and ferrous materials (Figure 1). Seven MBT plants have been currently working, while the three expected thermal treatment plants were under construction yet (Table 1).

The RDF plants were characterized by the same productive cycle, a two-step biostabilization, and they differed only in the number of treatment lines.

Particularly, the restwaste was treated by means of the following process phases (Belgiorno et al. [5]): 
- preliminary shredding of raw MSW;

- $\quad$ selection of shredded MSW in a first trommel screen obtaining a primary oversieve and a primary undersieve;

- magnetic separation and hand sorting of the primary oversieve, that was sent to the pressed RDF production line;

- $\quad$ selection of the primary undersieve in a second trommel screen, obtaining a secondary oversieve and a secondary undersieve;

- magnetic separation and then ballistic classification of the secondary oversieve, obtaining three fractions sent to the pressed RDF production line, composting line and landfill disposal respectively;

- controlled aerobic treatment of the fine fraction;

- eventual refinement of the stabilized organic fraction.

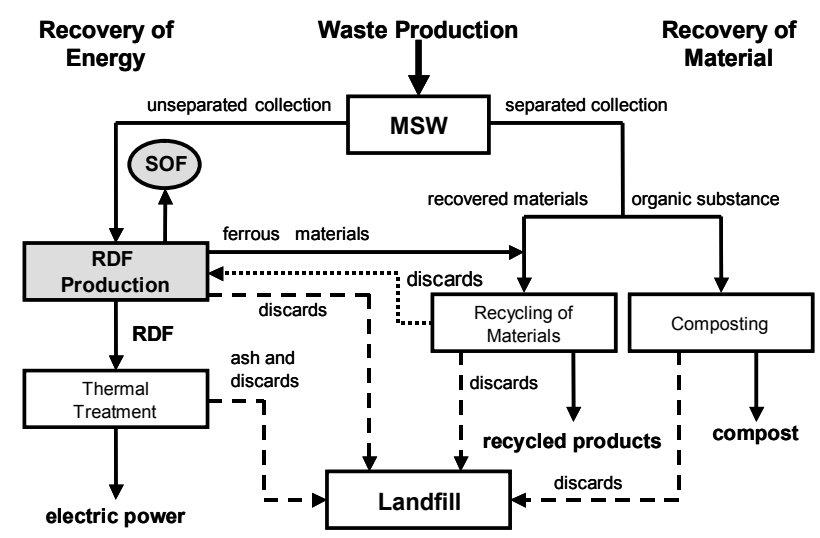

Figure 1: Integrated solid waste management system designed in Campania Region (Belgiorno et al. [5]).

Table 1: $\quad$ Characteristics of the MBT plants in the Campania Region (Panza et al. [1]).

\begin{tabular}{ccccc}
\hline N. & Localization & Capacity (t/y) & Working lines & Start up \\
\hline 1 & Caivano (Naples) & 607,000 & 4 & $8 / 13 / 2001$ \\
2 & Giugliano (Naples) & 451,500 & 3 & $2 / 4 / 2002$ \\
3 & Tufino (Naples) & 495,300 & 3 & $9 / 11 / 2002$ \\
4 & Pianodardine (Avellino) & 116,100 & 2 & $4 / 30 / 2001$ \\
5 & S.M. Capua Vetere (Caserta) & 361,700 & 2 & $11 / 5 / 2001$ \\
6 & Casalduni (Benevento) & 90,885 & 2 & $9 / 30 / 2002$ \\
7 & Battipaglia (Salerno) & 406,600 & 2 & $5 / 5 / 2003$ \\
\hline
\end{tabular}

Figure 2 shows the process with regard to the design mass balance.

The sheds for restwaste treatment and fine fraction composting were characterized by a slight negative pressure; the exhaust air was sucked up and sent to an odours treatment line, made up of vertical packed scrubbers and biofilters (Panza et al. [1]). 


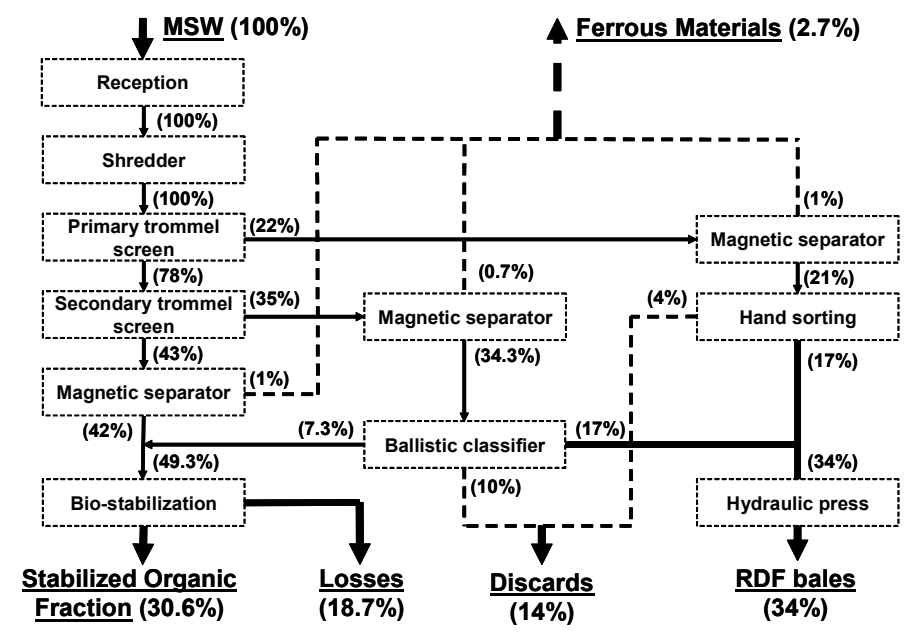

Figure 2: Design flow chart of RDF/Biostabilization plants in Campania Region (Panza et al. [1]).

The integrated MSW management system implemented in Campania Region was examined and assessed by the authors with regard to:

- characterization of MBT plants mass balances and products quality (Panza et al. [1]);

- discussion of RDF and SOF disposal options (Panza et al. [1], Belgiorno et al. [5]);

- impact assessment of SOF landfilling by means of characterization of leachate produced in pilot and real plants (Panza et al. [1], Belgiorno et al. [7])

Particularly, the regional MBT plants were characterized by comparing design mass balances, based on MSW composition contained in the Regional Plan for Solid Waste Disposal printed in 1997, with real mass balances obtained from data collection during the first four months of 2005. Moreover, Battipaglia MBT plant was further investigated by data collection during 2006.

Besides, leachate from a regional SOF landfill was sampled and analyzed during March 2005. The landfill was sited in Varcaturo, Province of Naples, and it received SOF produced by three MBT plants. The disposal was executed from June 2004 to April 2005. Leachate samples were withdrawn from the collection basin at the foot of the landfill.

Moreover, a SOF landfilling simulation in a pilot plant was carried out. The pilot plant, composed by a plexiglas cylindrical reactor (height of $1 \mathrm{~m}$; diameter of $0.25 \mathrm{~m}$ ), was filled by SOF until to $0.60 \mathrm{~m}$. It was realized with a geotextile sheet at the bottom and four leachate sampling points at different heights. Besides, it was covered by a soil layer with $0.10 \mathrm{~m}$ thickness at the open upper side. Leachate samples were monthly collected from the sampling point placed at the bottom of the reactor and analyzed according to Standard Methods (Figure 3). 


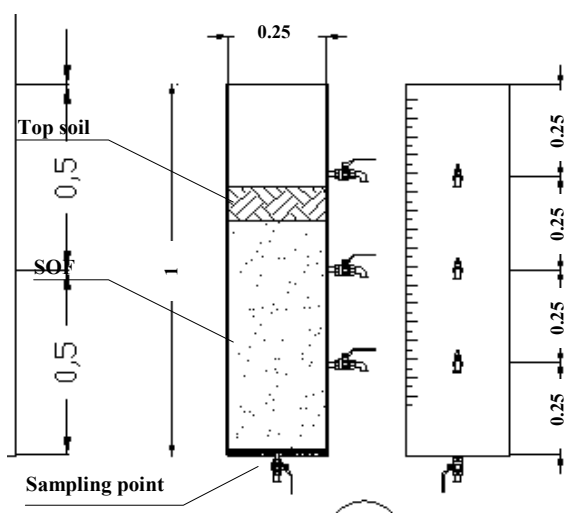

Figure 3: Pilot plant: SOF cylindrical reactor (Belgiorno et al. [7]).

\section{Results and discussion}

Figure 4 and Figure 5 respectively show the comparison between design mass balances and real ones for Campania Region and Battipaglia MBT plant..

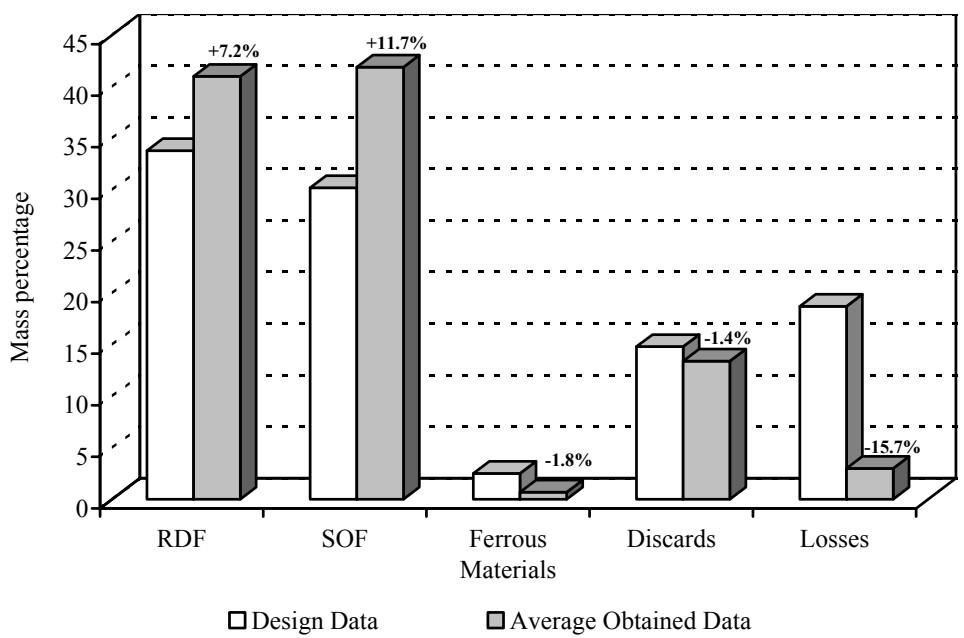

Figure 4: Comparison between design and production data for Campania Region (Panza et al. [1]).

Previous studies pointed out several results (Panza et al. [1], Belgiorno et al. [7]):

a. the obtained percentage of RDF was higher than the expected one, because of treatment of higher quantities of wastes;

b. the percentages of ferrous materials and discards were lower than design values; 
c. the quantity of SOF was considerably higher than the expected value. The variation is mainly related to differences between MSW design and real composition. Moreover, the lower value of aerobic process losses showed that duration of the biological treatment was short, so SOF was probably disposed of in high quantities with limited stabilization degree.

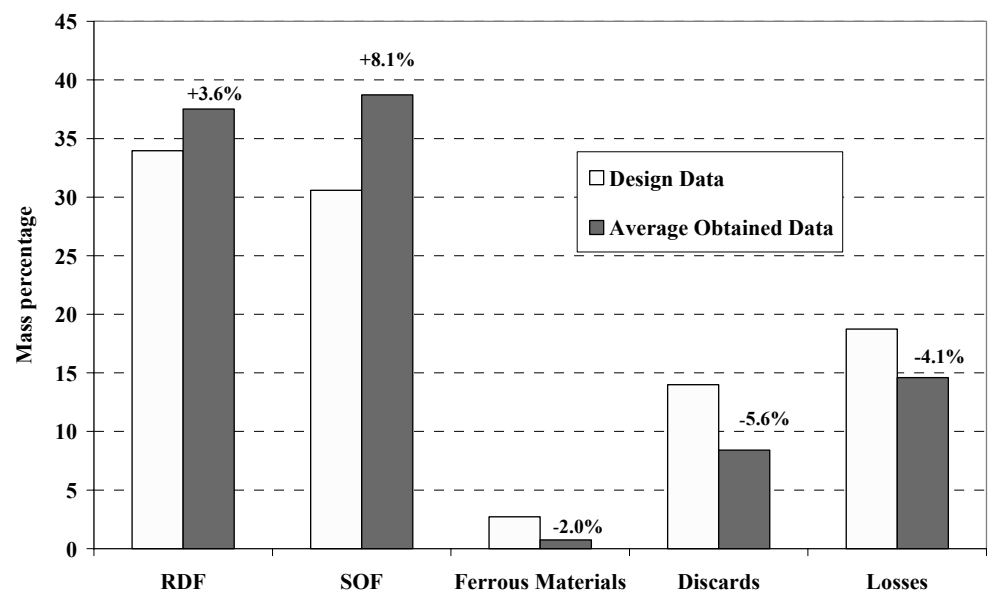

Figure 5: Comparison between design and production data for Battipaglia MBT plant (Belgiorno et al. [7]).

Chemical-physical characterization of SOF produced in Battipaglia plant (Table 2) showed that the material was not suitable for land use, since the investigated parameters differed from regulation limits (Belgiorno et al. [7]). In fact:

- the obtained percentage of organic content was lower than the limit value, as consequence of the poorly effective selection;

- the high carbon to nitrogen ratio $(\mathrm{C} / \mathrm{N})$ depended on both the low total nitrogen content and the insufficient aerobic stabilization of organic matter;

- the very low humic substances content showed the short duration of the biological process;

- high percentages of plastic materials were probably due to process selection ineffectiveness and high plastics content in the input waste flow;

- glasses content was related to shredding operations and low efficiency of ballistic separation;

- low percentage of ferrous materials suggested effective source and magnetic separations of metals. However, high heavy metals concentrations (Cr III, $\mathrm{Ni}, \mathrm{Pb}$ ) were found, probably due to poor selection of materials containing those compounds in the waste flow.

Comparison between design and real input waste composition confirmed the previous considerations (Table 3) (Belgiorno et al. [7]).

The quality of leachate from regional SOF landfill was compared with leachate produced by the pilot plant, in order to completely define the 
effectiveness of the MBT regional plants as well as more exactly understand SOF landfilling impact (Panza et al. [1], Belgiorno et al. [7]).

Table 2: Chemical and physical characteristics of SOF produced in Battipaglia plant (Belgiorno et al. [7]).

\begin{tabular}{|c|c|c|}
\hline Parameters & SOF values & Italian Regulation \\
\hline Moisture [\% d.s.] & 4,7 & $<45$ \\
\hline $\mathrm{pH}[-]$ & 7,8 & $6-8,5$ \\
\hline Organic Matter [\% d.s.] & 30,9 & $>40$ \\
\hline Humic substances [\% d.s.] & 1.5 & $>20$ \\
\hline Total N [\% d.s. $]$ & 0.51 & $>1$ \\
\hline $\mathrm{K}_{2} \mathrm{O}[\%$ d.s. $]$ & 0.39 & $>0.4$ \\
\hline $\mathrm{C} / \mathrm{N}[-]$ & 35.0 & $\leq 30$ \\
\hline As tot $[\mathrm{mg} / \mathrm{kg}$ d.s. $]$ & $<0.1$ & $\leq 10$ \\
\hline $\mathrm{Cd}$ tot $[\mathrm{mg} / \mathrm{kg}$ d.s. $]$ & $<0.1$ & $\leq 10$ \\
\hline Cr III [mg/kg d.s.] & 510 & $\leq 500$ \\
\hline $\mathrm{Cr}$ VI [mg/kg d.s.] & $<0.5$ & $\leq 10$ \\
\hline $\mathrm{Hg}$ tot $[\mathrm{mg} / \mathrm{kg}$ d.s. $]$ & 0.98 & $\leq 10$ \\
\hline Ni tot $[\mathrm{mg} / \mathrm{kg}$ d.s. $]$ & 300 & $\leq 200$ \\
\hline $\mathrm{Pb}$ tot $[\mathrm{mg} / \mathrm{kg}$ d.s. $]$ & 620 & $\leq 500$ \\
\hline $\mathrm{Cu}$ tot $[\mathrm{mg} / \mathrm{kg}$ d.s. $]$ & 126 & $\leq 600$ \\
\hline $\mathrm{Zn}$ tot $[\mathrm{mg} / \mathrm{kg}$ d.s. $]$ & 178 & $\leq 2,500$ \\
\hline Inerts $[\%$ d.s. $]$ & 3 & $\leq 3$ \\
\hline Plastics [\% d.s.] & 21.2 & $\leq 1$ \\
\hline Ferrous Materials [\% d.s.] & $<0.1$ & $\leq 0.5$ \\
\hline Glasses [\% d.s.] & 6.0 & $\leq 3$ \\
\hline Salmonella $[\mathrm{N} / 50 \mathrm{~g}]$ & 0 & 0 \\
\hline Infesting seeds $[\mathrm{N} / 50 \mathrm{~g}]$ & 0 & 0 \\
\hline
\end{tabular}

Table 3: Comparison between design and real content of metals, plastics, glasses in the input waste of Battipaglia plant (Belgiorno et al. [7]).

\begin{tabular}{ccc}
\hline Fraction & $\begin{array}{c}\text { Design percentage } \\
{[\% \text { weight }]}\end{array}$ & $\begin{array}{c}\text { Real percentage } \\
{[\% \text { weight }]}\end{array}$ \\
\hline Metals & 3.65 & 2 \\
Plastics & 12.50 & 25 \\
Glasses & 7.85 & 2 \\
\hline
\end{tabular}

Table 4 summarizes literature data of leachates produced by UMSWs (Untreated Municipal Solid Waste), MSOR (Mechanically Sorted Organic Residues), MBTs waste with a low/medium/high degree of composting and compares experimental results (Belgiorno et al. [7]).

Several considerations can be developed:

- $\mathrm{BOD}_{5}, \mathrm{COD}$ and $\mathrm{NH}_{3}$ values in the leachate from pilot plant confirmed that the produced SOF was not a stable material. Besides, $\mathrm{BOD}_{5}, \mathrm{COD}$ and $\mathrm{NH}_{3}$ values are more similar to UMSWs leachate than MSORs one; 
- $\quad$ high values of chlorides reflected the poorly effective sorting of the waste (plastics were clearly observable in the SOF samples (Table 3));

- poor selection and unsuitable aerobic process caused high metals concentrations. In general, metals concentrations depend on quantity in the input restwaste and solubilization processes. In leachate from pilot plant significant values of sodium, calcium, magnesium and potassium were observed, while iron, zinc, lead concentrations were not so high. Probably heavy metals contents reflected a reduced degree of solubilization for a still slightly low $\mathrm{pH}$ value.

Table 4: Characteristics of leachate from real and pilot plant and comparison with leachate produced by UMSWs, MSORs, MBTs waste (Belgiorno et al. [7]).

\begin{tabular}{|c|c|c|c|c|c|c|}
\hline Parameters ${ }^{(0)}$ & $\mathrm{UMSWs}^{(* *)}$ & $\operatorname{MSORs}^{(*)}$ & $\begin{array}{c}\text { MBTs wastes } \\
\text { (low-medium composting) }\end{array}$ & $\begin{array}{c}\text { MBTs waste } \\
\text { (high composting) }\end{array}$ & SL-FS & SL \\
\hline $\mathrm{pH}$ & 6.1 & 6 & 8 & 7.5 & 6.43 & 6.64 \\
\hline $\mathrm{BOD}_{5}$ & 13,000 & 100,000 & 110 & 50 & 14,156 & 18,750 \\
\hline COD & 22,000 & 150,000 & 3,000 & 2,000 & 96,350 & 30,000 \\
\hline $\mathrm{NH}_{3}$ & 750 & 4,000 & 525 & 30 & 2,606 & 1,030 \\
\hline Total P & 6 & 10 & 8 & 0.5 & 13.5 & 12.5 \\
\hline Alkalinity & 6,700 & 20,000 & 4,000 & 1,000 & 34,740 & 19,000 \\
\hline $\mathrm{Cl}$ & 2,100 & 8,000 & 6,000 & 1,000 & 21,768 & 3,600 \\
\hline $\mathrm{SO}_{4}$ & 500 & 1,000 & 3,000 & 500 & 2,884 & 26 \\
\hline $\mathrm{Cr}$ & 0.3 & 0.6 & 0.3 & 0.05 & 2.9 & 0.7 \\
\hline $\mathrm{Zn}$ & 5 & 10 & 1.75 & 0.5 & 42.25 & 0.7 \\
\hline As & 0.16 & 0.04 & 0.055 & 0.004 & 1.63 & $<0.5$ \\
\hline $\mathrm{Cd}$ & 0.006 & 1 & 0.0525 & 0.003 & 0.11 & $<0.1$ \\
\hline $\mathrm{Ca}$ & 1,200 & 6,000 & 450 & 250 & 8,050 & 3,200 \\
\hline $\mathrm{Fe}$ & 780 & 300 & 12.5 & 2 & 907.5 & 140 \\
\hline $\mathrm{Mg}$ & 470 & 1,000 & 250 & 60 & 727.5 & 510 \\
\hline $\mathrm{Mn}$ & 25 & 1.0 & 1.5 & 2 & 38.5 & 6.3 \\
\hline $\mathrm{Hg}$ & 0.01 & 0.0001 & 0.005 & 0.0001 & 0.1 & $<0.1$ \\
\hline $\mathrm{Ni}$ & 0.2 & 1 & 0.4 & 0.1 & 1.23 & 0.5 \\
\hline $\mathrm{Pb}$ & 0.09 & 0.3 & 0.25 & 0.02 & 0.95 & $<0.5$ \\
\hline $\mathrm{K}$ & 1,100 & 2,000 & 1,500 & 400 & 3,300 & 2,700 \\
\hline $\mathrm{Cu}$ & 0.08 & 0.5 & 0.35 & 0.2 & 0.25 & $<0.5$ \\
\hline $\mathrm{Na}$ & 1,350 & 4,000 & 3,000 & 800 & 3,325 & 2,900 \\
\hline \multicolumn{7}{|c|}{$\begin{array}{l}\left({ }^{\circ}\right) \text { All results in } \mathrm{mg} / \mathrm{L} \text { except } \mathrm{pH} \text { value and alkalinity } \mathrm{mgCaCO}_{3} / \mathrm{L} \\
(* *) \text { Average values of the parameters regarding to the acetogenic phase } \\
(*) \text { Typical values from a range of source data for the acetogenic phase } \\
\text { SL-FS: Average values of the parameters for the analyzed leachate from full scale SOF landfill } \\
\text { SL: Average values of the parameters for the analyzed leachate produced by pilot plant. }\end{array}$} \\
\hline
\end{tabular}

Regarding the RDF produced in Campania Region, it could be considered a baled RDF-2 with separation of inert and ferrous materials, according to the American Society for Testing and Materials (ASTM) classification (Manser and Keeling [8]). As a result, RDF with a low heating power value ranging between $12,000-13,000 \mathrm{~kJ} / \mathrm{kg}$ and a moisture content of about $25-30 \%$ was obtained in Campania. Those values did not respect the Italian regulation limits (minimum low heating power value equal to $15,000 \mathrm{~kJ} / \mathrm{kg}$; maximum moisture content equal to $25 \%$ ). 
RDF was manufactured in parallelepiped bales with a plastic polyethylene film. Bales had the following dimensions: $1.1 \mathrm{~m}$ in width, $1.1 \mathrm{~m}$ in height, 1.5 $\div 1.8 \mathrm{~m}$ in length. RDF density was $0.6-0.7 \mathrm{t} / \mathrm{m}^{3}$; weight was $1-1.5 \mathrm{t}$. Bales were tied with wires that concurred to preserve the material pressing efficiency.

While waiting for the three thermal treatment plants to be constructed, the produced RDF bales were transported to several regional storage sites where RDF was stored in pyramid shaped piles.

A previous study described the storage site in Caivano, Province of Naples (Belgiorno et al. [5]). The site covered an area of about 15 hectares and it was made up of 11 concrete platforms. The maximum storage capacity was about 255,000 bales. Each pyramid was made up of 9 rows of overlying bales (about $10 \mathrm{~m}$ in height) with a density of about 3 bales per $\mathrm{m}^{2}$ per platform.

The concrete platform was based on a sand drainage layer with an underlying $1 \mathrm{~mm}$ HDPE liner. It is worth noting that the proofing was placed only under the pyramids while it seemed to be absent in the manoeuvre lanes.

Perimeter channels to collect meteoric waters were dug around the platforms. During the building of each pyramid, meteoric waters were treated like leachate. As each single platform was filled, the pyramid was covered by means of an impermeable $1 \mathrm{~mm}$ HDPE liner, with thermally welded joints. Electronic sensors to control the temperature were placed in the pyramids under the covering. Due to the presence of a residual moisture content and the film wrapping, the selfcombustion of RDF stocked bales was improbable; however, an adequate antifire system for arson or accidental burning was necessary.

Particularly, the implementation of an incomplete management system due to the absence of thermal treatments plants had implied the following critical situation:

- $\quad$ about 75,000 tons of RDF bales produced per month;

- about 50,000 $\mathrm{m}^{2}$ per month used for bales storing;

- about 3.5 millions of RDF bales produced until to 2006 year;

- a period of 50 years for burning all the bales, in case of immediate activation of the thermal treatment plants.

\section{Conclusions}

According to Italian regulation, Campania Region, Southern Italy, adopted an integrated MSW management system based on recovery of source-separated organic and dry fractions and treatment of restwaste in seven mechanicalbiological plants, so to achieve refuse derived fuel, stabilized organic fraction and metals.

Quality of produced RDF and SOF was very poor due to the plants inefficiency and a low level of source-separated collection as well.

RDF bales with low heating power value and significant moisture content were stored in several regional sites in pyramid shaped piles, waiting for construction of the three expected thermal treatment plants.

SOF had to be reused in environmental restorations, but it was disposed of in worked-out quarries equipped like sanitary landfills due to its characteristics. It 
revealed limited biological stability, high percentages of inerts, plastics and glasses as well as significant concentrations of heavy metals. This assessment was confirmed by analyses carried out on leachate samples from SOF real and pilot plants.

\section{References}

[1] Panza, D., De Feo, G., Belgiorno, V. Quality of the stabilized organic fraction from mechanical and biological treatment. Proceedings Sardinia 2005, Tenth International Waste Management and Landfill Symposium, 3-7 October 2005, CISA publisher, S. Margherita di Pula, Cagliari, Italy.

[2] Bone, B. D., Knox, K., Picken, A., Robinson, H. D. The effect of mechanical and biological pre-treatment on landfill leachate quality. Proc. of Sardinia 2003, Ninth International Waste Management and Landfill Symposium, 6-10 October 2003, CISA publisher, S. Margherita di Pula, Cagliari, Italy.

[3] Bockreis, A., Steinberg, I., Rohde, C., Jager, J. Gaseous emissions of mechanically-biologically pre-treated waste from long-term experiments. Proc. of Sardinia 2003, Ninth International Waste Management and Landfill Symposium, 6-10 October 2003, CISA publisher, S. Margherita di Pula, Cagliari, Italy

[4] Heiss-Ziegler, C., Fehrer, K. Geotechnical behaviour of mechanicallybiologically pre-treated municipal solid waste (MSW). Proc. of Sardinia 2003, Ninth International Waste Management and Landfill Symposium, 6-10 October 2003, CISA publisher, S. Margherita di Pula, Cagliari, Italy

[5] Belgiorno, V., De Feo, G., Panza, D., Napoli, R. M. A. An "alternative" disposal for refuse derived fuel. Proc. of Sardinia 2003, Ninth International Waste Management and Landfill Symposium, 6-10 October 2003, CISA publisher, S. Margherita di Pula, Cagliari, Italy

[6] Soyez, K., Plickert, S. Material flux management of waste by mechanicalbiological pre-treatment. Proc. of Sardinia 2003, Ninth International Waste Management and Landfill Symposium, 6-10 October 2003, CISA publisher, S. Margherita di Pula, Cagliari, Italy

[7] Belgiorno, V., Panza, D., Amodio, V., Russo, L. MSW stabilized organic fraction landfilling. Proc. of Sardinia 2007, Eleventh International Waste Management and Landfill Symposium, 1-5 October 2007, CISA publisher, S. Margherita di Pula, Cagliari, Italy

[8] Manser, A.G.R., Keeling, A.A. Processing and Recycling Municipal Waste. CRC Press, Inc., 1996. 